УДК 504.55.054: 622 (470.6)

\title{
ЭКСПЕРИМЕНТАЛЬНОЕ ИССЛЕДОВАНИЕ КАЧЕСТВА ДРОБЛЕНИЯ РУД ДЛЯ ПОДЗЕМНОГО ВЫЩЕЛАЧИВАНИЯ
}

\author{
Голик Владимир Иванович1,2, \\ info@skgmi-gtu.ru
}

\section{Разоренов Юрий Иванович2,} rektorat@npi-tu.ru

\author{
Комащенко Виталий Иванович2, \\ komashchenko@inbox.ru
}

\section{Бурдзиева Ольга Германовна ${ }^{1}$, cgi_ras@mail.ru}

1 Геофизический институт Владикавказского научного центра Российской академии наук, Россия, 362002, г. Владикавказ, ул. Маркова, 93а.

2 Южно-Российский государственный политехнический университет, Россия, 346428, г. Новочеркасск, ул. Просвещения, 132.

\begin{abstract}
Актуальность исследования вызвана необходимостью поиска новых путей для увеличения производства металлов. Объёмы некондиционных по содержанию металлов руд новых и строящихся месторождений техногенных массивов могут быть вовлечены в производство с повышением безотходности освоения недр.

Цель: повышение качества взрывного дробления руд для подземного выщелачивания металлов путем экспериментального обоснования параметров отделения от массива и дробления металлических руд.

объект: рудовмещающий массив и технологические процессы отбойки и дробления руд конкретного месторождения в ходе полномаситабного эксперимента в опытном блоке.

Методология: критический анализ теории и практики отбойки и дробления руд для выщелачивания в магазине, организация мониторинга выщелачиваемого массива в ходе извлечения металлов, моделирование и интерпретация результатов исследований.

Результаты. Дана краткая справка по истории вопроса. Описана методика осуществления промышленного эксперимента на месторождении вскрываемых руд. Систематизированы показатели взрывной отбойки руд в процессе их магазинирования. Предложен критерий дробимости руд взрывом. Выполнена математическая обработка результатов взрывной отбойки руды. Показано, что способ выщелачивания даже при коэфффициенте извлечения 70 \% не конкурирует с традиционными технологиями из-за потери полезного компонента и требует совершенствования. Установлены закономерности распределения полезного компонента в классах отбитой руды, описываемые логарифмически-нормальным законом Гаусса. Показано, что размер куска, который соответствует среднеарифметическому значению содержания полезного компонента объективно характеризует качество отбитой для подземного выщелачивания руды. Сформулировано отличие предлагаемого метода от традиционного расчета средневзвешенного линейного размера, не учитывающего неравномерность распределения металла между фрракциями. Предложена обобщенная модель взрывной подготовки руд к выщелачиванию. Изучение распределения содержания полезного компонента в отбитой руде в зависимости от вещественного состава, характера минерализации, общего содержания металла в рудовмещающих породах, технологии рудоподготовки может оказать существенное влияние на показатели выщелачивания.
\end{abstract}

\section{Ключевые слова:}

Промышленный эксперимент, месторождение, руда, металл, взрывная отбойка, дробимость, выщелачивание, извлечение, распределение компонента, размер куска, содержание, модель.

\section{Введение}

Концепция удовлетворения потребности промышленности в металлах включает в себя положения об усилении спроса на металлосодержащее сырье, уменьшении запасов месторождений в комфортных для эксплуатации районах, усложнении условий разработки при понижении на глубину, необходимости защиты экосистем окружающей среды и земной поверхности от разрушения. Проблема обеспечения промышленности минеральным сырьем весьма актуальна и для России [1-3].

Решение этой проблемы делает необходимым активизацию исследований, направленных на поиски резервов получения металлов [4-6].
Среди технологий, отвечающих этим требованиям права гражданства завоевывают варианты с подземным выщелачиванием руд, прежде всего, цветных металлов, в блоках [7-9].

Эти технологии позволяют без крупных капиталовложений, используя имеющуюся инфраструктуру, увеличить запасы сырья, использовать хвосты выщелачивания для управления горным давлением, продлить срок эксплуатации действующих месторождений и существенно уменьшить ущерб окружающей среде.

Подземным блоковым выщелачиванием добывают медь на месторождениях (Гумешевское), молибден попутно с ураном (Стрельцовское), обеспечивая большую часть производственной программы и на 
отдельных участках других месторождений вскрываемых руд.

Новая технология нуждается в научном обосновании, включающем, в том числе, оценку распределения содержания полезного компонента в отбитой руде в зависимости от вещественного состава, характера минерализации, общего содержания металла в рудовмещающих породах и др.

Для разработки новых технологий характерна большая доля исследований по эффективности отделения от массива и дробления руд на этапе подготовки их к выщелачиванию [10-12].

Промышленный многофакторный эксперимент по выщелачиванию металлов из балансовых комплексных руд осуществлен в опытном блоке месторождения Северного Казахстана.

\section{Исследование и обсуждение результатов}

Вмещающие породы месторождения представлены вулканогенными-осадочными и осадочными породами. Коэффициент крепости вмещающих пород от 7-8 до 1-5 в зоне разломов. Рудовмещающими породами являются аргиллиты и алевролиты верхнего ордовика, слабо метаморфизованные, грубо слоистые и рассланцованные.

Рудная залежь представляет собой линзовидное тело длиной 350-370 м, прослеженное на глубину до 950 м с углом падения 55-65․ Мощность залежи составляет 45-50 м в центре со снижением на флангах. Объемная плотность руды и пород 2,7 т/ $\mathrm{m}^{3}$. Основные запасы отработаны вариантами с принудительным обрушением руд и пород.

Подготовка руды к подземному выщелачиванию на первом этапе промышленного эксперимента предусматривала расширение отрезного восстающего на полную ширину блока и образование компенсационного пространства.

В районе отрезного восстающего дренажнобуровые выработки сбили рассечками, а из образовавшейся подсечки бурили глубокие скважины на высоту блока, которые были взорваны в два приема.

Отбитая горная масса была выпущена. В блоке было обурено пять полных вееров скважин на горизонтах 189 и 212 м. Количество и глубина скважин в полувеерах изменялись в зависимости от конфигурации рудного тела. Число замедлений в полувеерах изменялось от двух до трех. В качестве взрывчатого вещества (ВВ) применяли гранулит 79/21, а в боевиках - аммонал АВ-200.

Коэффициент разрыхления руды составил 1,34.

Первый веер обурили на всю высоту блока и взорвали на открытое пространство, а остальные пять взрывали поочередно без частичного выпуска руды. Расстояние между веерами скважин оставалось постоянным.

Качество дробления определяли методом фотопланиметрии 6 раз за 1 взрывание и оценивали по выходу классов 0-50; (+50)-100; (+100)-150 и (+200) мм.

В табл. 1 даны результаты исследования.

Таблица 1. Показатели взрывной отбойки руды

Table 1. Indicators of explosive ore breaking

\begin{tabular}{|c|c|c|c|c|c|c|c|}
\hline \multirow{2}{*}{ Показатели/Indicators } & \multirow{2}{*}{$\begin{array}{l}\text { Единицы } \\
\text { Units }\end{array}$} & \multicolumn{5}{|c|}{ Веера скважин/Well fans } & \multirow{2}{*}{$\begin{array}{l}\text { Cреднее } \\
\text { Average }\end{array}$} \\
\hline & & 1 & 2 & 3 & 4 & 5 & \\
\hline $\begin{array}{l}\text { Объем отбитой руды } \\
\text { Ore chipped off }\end{array}$ & $\mathrm{m}^{3} / \mathrm{m}^{3}$ & 580 & 630 & 530 & 670 & 250 & - \\
\hline $\begin{array}{l}\text { Удельный расход гранулита } \\
\text { Specific consumption of granulite }\end{array}$ & $\begin{array}{l}\mathrm{K} \Gamma / \mathrm{M}^{3} \\
\mathrm{~kg} / \mathrm{m}^{3}\end{array}$ & 1,0 & 0,9 & 1,6 & 1,4 & 1,6 & 1,27 \\
\hline $\begin{array}{l}\text { Коэффициент сближения } \\
\text { Convergence ratio }\end{array}$ & - & 1,1 & 0,7 & 0,8 & 0,7 & 0,9 & 0,83 \\
\hline $\begin{array}{l}\text { Выход отбитой руды } \\
\text { Broken ore yield }\end{array}$ & $\begin{array}{l}\mathrm{M}^{3} / \mathrm{M} \\
\mathrm{m}^{3} / \mathrm{m}\end{array}$ & 3,4 & 4,2 & 3,0 & 3,7 & 3,6 & 3,38 \\
\hline $\begin{array}{l}\text { Выход фракции 0-50 мм } \\
\text { Output of 0-50 mm fraction }\end{array}$ & \multirow{6}{*}{$\%$} & 66,6 & 52,4 & 64,1 & 70,6 & 66,9 & 64,1 \\
\hline $\begin{array}{l}\text { Выход фракции (+50)-100 мм } \\
\text { Output of }(+50)-100 \mathrm{~mm} \text { fraction }\end{array}$ & & 12,0 & 13,0 & 14,3 & 17,4 & 24,4 & 16,2 \\
\hline $\begin{array}{l}\text { Выход фракции (+100)-150 мм } \\
\text { Output of }(+100)-150 \mathrm{~mm} \text { fraction }\end{array}$ & & 8,5 & 4,6 & 8,8 & 6,6 & 3,8 & 6,5 \\
\hline $\begin{array}{l}\text { Выход фракции (+150)-200 мм } \\
\text { Output (+150)-200 mm fraction }\end{array}$ & & 10,3 & 10,4 & 3,2 & 2,3 & 2,6 & 5,8 \\
\hline $\begin{array}{l}\text { Выход фракции (+200) мм } \\
\text { Output of }(+200) \text { mm fraction }\end{array}$ & & 2,6 & 19,6 & 9,6 & 3,1 & 2,3 & 7,4 \\
\hline $\begin{array}{l}\text { Выход фракции }(0-50)+(+150-200) \text { мм } \\
\text { Output of }(0-50)+(+150-200) \text { mm fraction }\end{array}$ & & 97,4 & 80,4 & 90,4 & 96,9 & 97,7 & 92,6 \\
\hline $\begin{array}{l}\text { Средний размер куска } \\
\text { Average piece size }\end{array}$ & мм/mm & 60,3 & 115,4 & 76,9 & 53,8 & 52,3 & 72,3 \\
\hline $\begin{array}{l}\text { Критерий дробимости } \\
\text { Crushing criterion }\end{array}$ & - & 3,9 & 3,3 & 3,7 & 4,0 & 4,5 & - \\
\hline
\end{tabular}

На долю класса 0-50 пришлось 64 \%, выход класса 200-300 мм составил $7 \%$, доля класса 0-200 составила $93 \%$, а доля кусков 400 мм составила всего 1,5\%. Размер средневзвешенного куска изменялся от 52 до 78 мм.
Критерий дробимости может быть описан выражением:

$$
L=\ln \frac{W}{d},
$$

где $d$ - средневзвешенный размер куска. 
Лучший показатель дробления получен при взрывании вееров в «зажиме» с коэффициентом разрыхления 1,35-1,4.

Построена кривая распределения руды по классам крупности, из которой видно, что в интервале выхода кондиционных классов 0-200 мм закономерность подчиняется закону Гаусса. Это говорит о том, что установленные параметры буровзрывных работ могут обеспечить состав горной массы с идентичным выходом нужных классов.

Эффективность добычи металлов зависит от полноты извлечения полезного ископаемого из недр. При отработке балансовых запасов способ выщелачивания даже при извлечении 70 \% металлов пока не конкурирует с традиционными технологиями.

Для повышения эффективности добычи руды стремятся увеличить степень ее дробления, но при выщелачивании мелкоизмельченная руда спрессовывается и не прорабатывается выщелачивающим раствором реагента, что увеличивает потери металлов.

В рамках исследований решали задачи: определение содержания и суммарного количества полезного компонента в гранулометрических классах отбитой руды и расчет извлечения и времени выщелачивания при фактическом составе отбитой руды.

Эксперимент осуществлен с использованием геофизической аппаратуры в отстоящей от блока на 200 м камере с поддержанием постоянной температуры и влажности.

После отбойки отбирали руду по классам крупности, мм: 0-50, 50-100, 150-200, 200-300, 300-400 и более, и загружали в металлический контейнер размерами $35 \times 50 \times 50$ см с регистрирующими датчиками.

Время измерений одной порции принималось равным 100 с, а количество замеров - 3. Всего выполнено 120 определений проб общей массой 6000 кг.

Среднее содержание метала в классах 200-400 мм в 5 раз ниже, чем в оптимальном для выщелачивания классе 0-200 мм, а суммарное количество в них металла превышает $92 \%$ от всего количества. Установлено, что содержание полезного компонента в отбитой руде с увеличением размера кусков снижается (рис. 1).

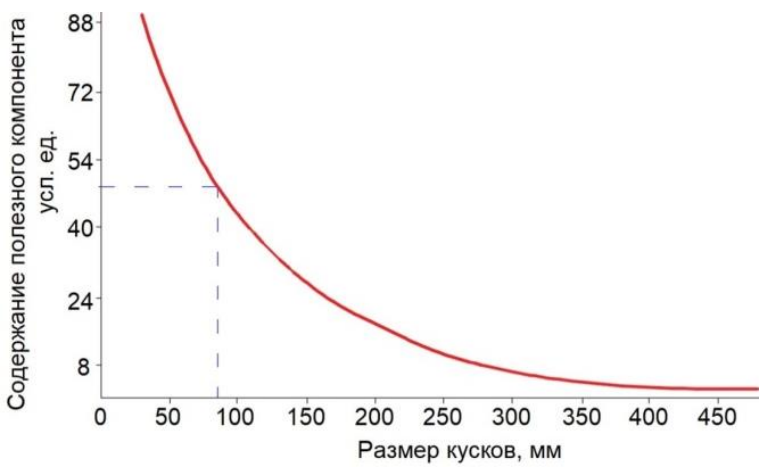

Puc. 1. Распределение содержания металлов в руде в зависимости от крупности

Fig. 1. Distribution of metal content in ore depending on size
Результаты измерений в блоке и в других выработках обнаруживают хорошую сходимость данных опробования блока с данными ранее выполненной геологической разведки выработок (табл. 2).

Таблица 2. Сопоставление показателей содержания металлов

Table 2. Comparison of metal content indicators

\begin{tabular}{|c|c|c|c|c|c|c|}
\hline \multirow{2}{*}{$\begin{array}{c}\text { Классы } \\
\text { Classes }\end{array}$} & \multicolumn{2}{|c|}{$\begin{array}{c}\text { Содержание, y.e. } \\
\text { Content, c.u. }\end{array}$} & $\begin{array}{c}\text { Количество } \\
\text { проб } \\
\text { Number of sam- } \\
\text { ples }\end{array}$ & $\begin{array}{c}\text { Средневзвешенное } \\
\text { содержание, у.e. } \\
\text { Weighted average } \\
\text { content, c.u. }\end{array}$ \\
\cline { 2 - 8 } & $\begin{array}{c}\text { Блок } \\
\text { Вlock }\end{array}$ & $\begin{array}{c}\text { Выра- } \\
\text { ботки } \\
\text { Workings }\end{array}$ & $\begin{array}{c}\text { Блок } \\
\text { Block }\end{array}$ & $\begin{array}{c}\text { Выработ- } \\
\text { ки } \\
\text { Workings }\end{array}$ & $\begin{array}{c}\text { Блок } \\
\text { Block }\end{array}$ & $\begin{array}{c}\text { Выработки } \\
\text { Workings }\end{array}$ \\
\hline $0-50$ & 80,4 & 62,0 & 16 & 12 & 67,6 & 32,9 \\
\hline $50-100$ & 40,4 & 35,2 & 16 & 12 & 6,0 & 5,3 \\
\hline $100-150$ & 36,8 & 25,6 & 16 & 12 & 2,7 & 1,4 \\
\hline $150-200$ & 31,6 & 20,8 & 16 & 12 & 1,8 & 0,9 \\
\hline $200-300$ & 15,1 & 13,3 & 13 & 9 & 0,5 & 0,1 \\
\hline $300-400$ & 6,2 & 0 & 9 & 5 & 0,2 & 0 \\
\hline$\geq 400$ & 14,0 & 0 & 8 & 5 & 0,2 & 0 \\
\hline
\end{tabular}

Примечание: у.е. - условная единица содержания металлов.

Note: c.u. - conventional unit of metal content.

Из таблицы можно сделать вывод, что основная масса металлов извлекается из классов крупностью до 50 мM.

Таблица 3. Полнота извлечения металлов

Table 3. Completeness of metal extraction

\begin{tabular}{|c|c|c|c|c|c|c|}
\hline \multirow{2}{*}{$\begin{array}{c}\text { Класс, } \\
\text { мм } \\
\text { Class, } \\
\text { mm }\end{array}$} & \multirow{2}{*}{ 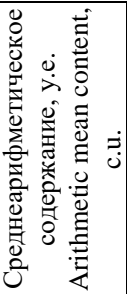 } & \multirow{2}{*}{ 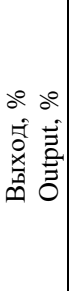 } & \multirow{2}{*}{ 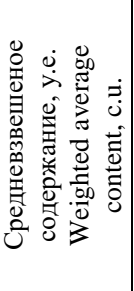 } & \multirow{2}{*}{ 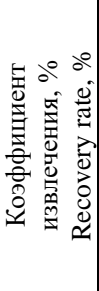 } & \multicolumn{2}{|c|}{$\begin{array}{c}\text { Средневзвешен- } \\
\text { ное извлечение } \\
\text { по блоку } \\
\text { Weighted average } \\
\text { recovery by block }\end{array}$} \\
\hline & & & & & y.e./c.u. & $\%$ \\
\hline $0-50$ & 72,0 & 64,1 & 46,1 & 93,0 & 42,8 & 73,7 \\
\hline $50-100$ & 36,0 & 16,2 & 5,8 & - & - & - \\
\hline $100-150$ & 32,0 & 6,5 & 2,1 & 64,0 & 5,0 & 8,6 \\
\hline $150-200$ & 28,0 & 5,8 & 1,6 & 41,0 & 0,7 & 1,2 \\
\hline $200-300$ & 7,2 & 4,0 & 0,3 & - & - & - \\
\hline $300-400$ & 5,6 & 2,0 & 0,1 & - & - & - \\
\hline+400 & 9,7 & 1,3 & 0,1 & - & - & - \\
\hline-200 & 42,0 & - & 56,2 & - & - & - \\
\hline+200 & 6,1 & - & - & - & - & - \\
\hline
\end{tabular}

Для доказательства случайно-вероятного характера распределения содержания полезного компонента в отбитой руде по гранулометрическим классам обработаны руды восьми месторождений с проверкой распределения на нормальность.

Установленная закономерность описывается законом Гаусса. На рис. 2 дано распределение содержания металла в логарифмических координатах для руд исследуемого месторождения в сравнении с аналогичными рудными месторождениями, причем их графики интерпретируются прямыми линиями.

Из известного закона Гаусса следует, что наилучшим приближением к истинному значению измеряемой величины гранул является средняя арифметическая величина. 


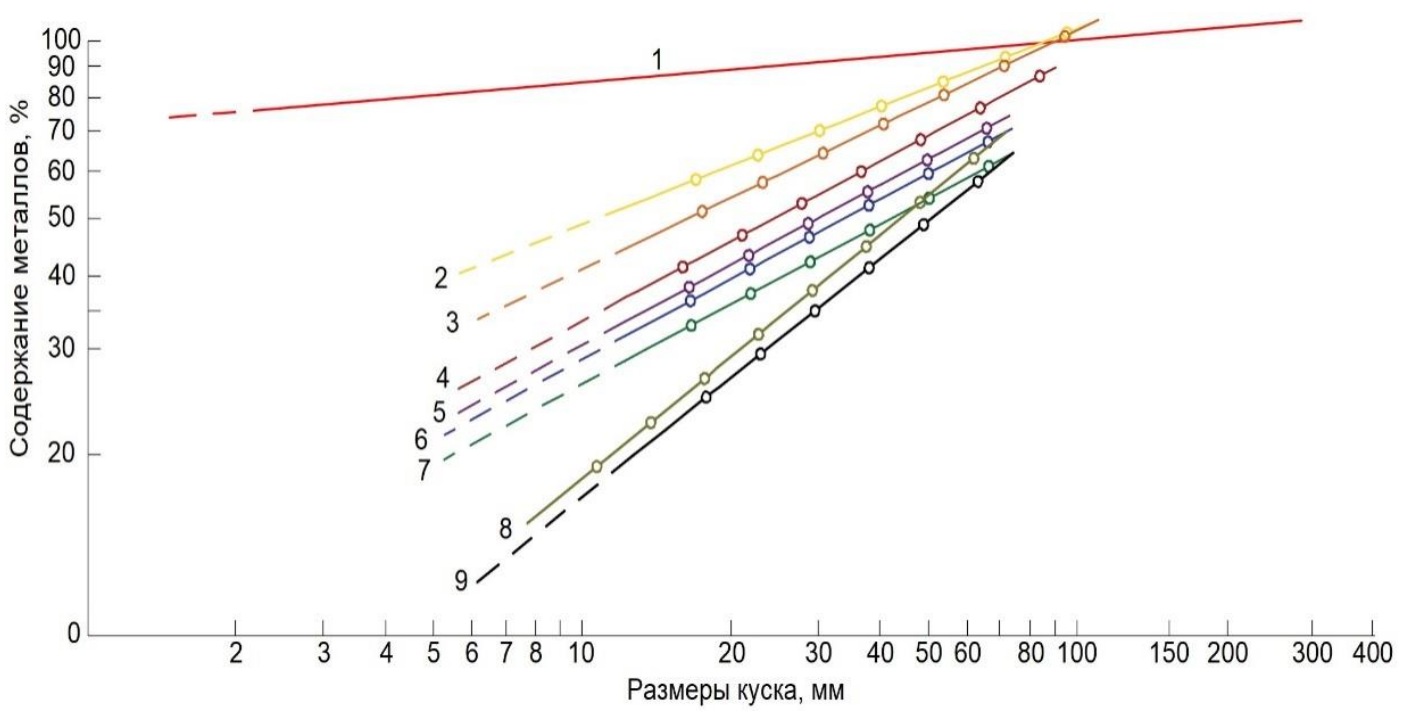

Рис. 2. Графики распределения содержания металла в логарифмических координатах: 1 -руда исследуемого месторождения; 2-9-руды аналогичных месторождений

Fig. 2. Graphs of metal content distribution in logarithmic coordinates: 1 - ore of the investigated deposit; 2-9-ores of similar deposits

Следовательно, размер куска, который соответствует среднеарифметическому значению содержания полезного компонента в искомом составе наиболее объективно отражает качество отбитой для подземного выщелачивания руды. Этим предлагаемый метод отличается от ранее известного метода расчета средневзвешенного линейного размера рудного куска, который не учитывает равномерность распределения металла по классам.

Пример: Проба руды состоит из кусков размером 4 и 10 см с равным массовым их соотношением, но куски размером 4 см содержат полезный компонент (пусть во всех кусках содержание одинаковое), а в кусках 10 см он отсутствует. Определим кусок, размер которого в наибольшей степени характеризует данную пробу с точки зрения полноты извлечения из нее металла выщелачиванием.

Средневзвешенный линейный размер, рассчитанный по известному методу:

$$
\alpha=4 \cdot 0,5+10 \cdot 0,5=7 \text { cм. }
$$

Размер куска, соответствующий среднему арифметическому содержанию, составляет 4 см.

При оценке пробы по средневзвешенному линейному размеру допускается неточность в определении коэффициента извлечения при выщелачивании, поскольку он не характеризует куски с точки зрения их вещественного состава.

Для рассматриваемого конкретного гранулометрического состава среднее значение содержания полезного компонента по данным наших измерений составило 56,20 у.ед. Эта величина находится в интервале кусков от 0 до 15 мм. Середина этого интервала, т. е. 75 мм, является наилучшим приближением к истинному значению среднегармонического куска, который с наибольшей достоверностью характеризует свойства полученного в блоке гранулометрического состава.
Качество дробления руды для выщелачивания в подземных блоках является одним из определяющих факторов эффективности системы разработки. Поэтому установление корреляции между параметрами локализации рудных тел в пространстве, свойствами руд и возможностями взрывного дробления является темой многих исследований по данному направлению горного дела [13-16].

Искомые параметры описываются обобщенной моделью:

$$
q=\frac{1800 \cdot 10^{6} \sqrt{f} \delta \frac{P}{1-P}\left(\frac{M_{n}}{M_{o}}-1\right)+\frac{\gamma}{2 g} \ln \frac{K_{p}}{1+P} C_{0}^{2}}{Q_{v}^{1+\eta}},
$$

где $F$ - коэффициент крепости пород; $\gamma$ - плотность, т $/ \mathrm{M}^{3} ; \delta$ - ширина раскрытия щели, или толщина диффузного слоя при естественной конвенции; $P$ - объемная пористость нарушенного рудного массива при минимальном раскрытии трещин; $M_{o}$ - удельная поверхность средневзвешенного куска в целике, $10 \mathrm{~m}^{-1}$; $M_{n}$ - удельная поверхность средневзвешенного куска после взрывания, $10 \mathrm{~m}^{-1} ; K_{p}$ - коэффициент разрыхления руды; $C_{0}-$ начальная скорость разлета руды при взрывании, м/с; $Q_{v}$ - потенциальная энергия ВВ для гранулированных ВВ, Дж; $\eta$ - коэффициент эффективности ВВ.

Конверсия технологий добычи руд сопровождается совершенствованием процессов в сопряженных отраслях хозяйственной системы [17-20].

\section{Заключение}

Объёмы некондиционных по содержанию металлов руд новых и строящихся месторождений техногенных массивов могут быть вовлечены в производство при обеспечении качества взрывного дробления руд для подземного выщелачивания, что подтверждается результатами многофакторного промышленного 
эксперимента при разработке сложноструктурного месторождения.

Изучение распределения содержания полезного компонента в отбитой руде в зависимости от вещественного состава, характера минерализации, общего

\section{СПИСОК ЛИТЕРАТУРЫ}

1. Минерально-сырьевая база цветной металлургии России Ю.В. Дмитрак, Б.С. Цидаев, В.Х. Дзапаров, Г.Х. Харебов // Вектор ГеоНаук. - 2019. - Т. 2. - № 1. - С. 9-18.

2. Повышение экономической эффективности горнодобывающих предприятий за счет вовлечения в эксплуатацию техногенных георесурсов / С.Е. Гавришев, С.Н. Корнилов, И.А. Пыталев, И.В. Гапонова // Горный журнал. - 2017. № 12. - C. 46-51.

3. Espinoza R.D., Rojo J. Towards sustainable mining. P. I. Valuing investment opportunities in the mining sector // Resource Policy. 2017. - V. 52. - P. 7-18.

4. Голик В.И., Лукьянов В.Г., Хашева З.М. Обоснование возможности и целесообразности использования хвостов обогащения руд для изготовления твердеющих смесей // Известия Томского политехнического университета. - 2015. - Т. 326. № 5. - C. 6-14.

5. Комплексный анализ применения эффективных технологий для повышения устойчивого развития природно-технической системы / Р.В. Клюев, И.И. Босиков, А.В. Майер, О.А. Гаврина // Устойчивое развитие горных территорий. - 2020. - № 2. C. $283-290$.

6. Re-thinking mining waste through an integrative approach led by circular economy aspirations / M. Tayebi-Khorami, M. Edraki, G. Corder, A. Golev // Minerals. - 2019. - V. 9. - P. 1-13. DOI $10.3390 / \min 9050286$

7. Lyashenko V.I., Golik V.I., Komashchenko V.I. Increasing the efficiency of drilling and blasting preparation of rock ores for underground block leaching of metals // Scientific and technical journal «Explosion Technology». - 2018. - № 120/77. P. 147-168.

8. Dubiński J. Sustainable development of mining mineral resources // International Journal of Sustainable Future for Human Security. 2013. - V. 12. - № 1. - P. 1-6.

9. Извлечение меди из рудничных вод Гумешевского месторождения / И.А. Алтушкин, Ю.А. Король, В.В. Левин, А.В. Бакин // Цветные металлы. - 2019. - № 6. - C. 13-21. DOI: $10.17580 /$ tsm.2019.06.02

10. Отбойка руд скважинными зарядами модернизированной конструкции / В.И. Комащенко, В.Х. Дзапаров, Б.В. Дзеранов, Г.В. Стась // Вектор ГеоНаук. - 2019. - Т. 2. - № 3. - С. 40-46.

11. Повышение эффективности взрывной отбойки на основе новых способов инициирования скважинных зарядов на карьеpax / В.И. Комащенко, В.И. Голик, В.А. Белин, А.Л. Гапонен- содержания металла в рудовмещающих породах, технологии рудоподготовки в блоках подземного выщелачивания может оказать существенное влияние на параметры систем выщелачивания и отдельных технологических процессов и дать практические результаты.

ко // Горный информационно-аналитический бюллетень (научно-технический журнал). - 2014. - № 9. - С. 293-304.

12. Дмитрак Ю.В., Камнев Е.Н. АО «Ведущий проектноизыскательский и научно-исследовательский институт промышленной технологии» - путь длиной в 65 лет // Горный журнал. - 2016. - № 3. - С. 6-12.

13. Evidences of the influence of the detonation sequence in rock fragmentation by blasting. P. I / M. Cardu, J. Seccatore, A. Vaudagna, A. Rezende, F. Galvão, J.S. Bettencourt, G. de Tomi // REM: RevistaEscola de Minas. - 2015. - V. 68. - № 3. P. 337-342. DOI: 10.1590/0370-44672014680218.

14. Integration of underground mapping, petrology, and highresolution microseismicity analysis to characterise weak geotechnical zones in deep South African gold mines / S.B. Mngadi, R.J. Durrheim, M.S.D. Manzi, H. Ogasawara, Y. Yabe et al. // International Journal of Rock Mechanics and Mining Sciences. - 2019. - V. 114. - P. 79-91.

15. Пространственно-временные задачи геоэкологии - междисциплинарный подход / В.С. Бригида, Х.Х. Кожиев, А.А. Сарян А.К. Джиоева // Горный информационно-аналитический бюллетень. - 2020. - № 4. - C. 20-32. DOI: 10.25018/023614932020-4-0-20-32.

16. Бурмистров К.В., Осинцев Н.А. Принципы устойчивого развития горнотехнических систем в переходные периоды // Известия Томского политехнического университета. Инжиниринг георесурсов. - 2020. - Т. 331. - № 4. - С. 179-195.

17. Strategic mining options optimization: Open pit mining, underground mining or both / E. Ben-Awuah, O. Richter, T. Elkington, Y. Pourrahimian // International Journal of Mining Science and Technology. - 2016. - V. 26. - № 6. - P. 1065-1071.

18. Domingues Maria S.Q., BaptistaAdelina L.F., Diogo Miguel Tato. Engineering complex systems applied to risk management in the mining industry // International Journal of Mining Science and Technology. - 2017. - V. 27. - P. 611-616.

19. Роботизированные геотехнологии как путь повышения эффективности и экологизации освоения недр / М.В. Рыльникова, Д.Я. Владимиров, И.А. Пыталев, Т.М. Попова // Физикотехнические проблемы разработки полезных ископаемых. 2017. - № 1. - C. 92-101.

20. Woodward K., Wesseloo J. Observed spatial and temporal behaviour of seismic rock mass response to blasting // Journal of the Southern African Institute of Mining and Metallurgy. - 2015. V. 115. - № 11. - P. 1044-1056.

\section{Информация об авторах}

Голик В.И., доктор технических наук, профессор, главный научный сотрудник Геофизического института Владикавказского научного центра Российской академии наук; профессор кафедры горного дела ЮжноРоссийского государственного политехнического университета.

Разоренов Ю.И., доктор технических наук, профессор, ректор Южно-Российского государственного политехнического университета.

Комащенко В.И., доктор технических наук, профессор, профессор кафедры горного дела Южно-Российского государственного политехнического университета.

Бурдзиева О.Г., кандидат географических наук, заведующая лабораторией техногенной геоэкологии Геофизического института Владикавказского научного центра Российской академии наук. 
UDC 504.55.054: $622(470.6)$

\title{
EXPERIMENTAL STUDY OF THE QUALITY OF ORE CRUSHING FOR UNDERGROUND LEACHING
}

\author{
Vladimir I. Golik ${ }^{1,2}$, \\ v.i.golik@mail.ru \\ Yuri I. Razorenov², \\ yiri1963@mail.ru \\ Vitaly I. Komashchenko², \\ komashchenko@inbox.ru \\ Olga G. Burdzieva1, \\ olgaburdzieva@mail.ru \\ 1 Geophysical Institute of the Vladikavkaz Scientific Centre of hte Russian Academy of Sciences, \\ 93a, Markov street, Vladikavkaz, 362002, Russia. \\ 2 South Russian State Polytechnic University, \\ 132, Prosvyashcheniya street, Novocherkassk, 346428, Russia.
}

The relevance of the study is caused by the need to find new ways to increase the production of metals. The volumes of substandard ores in terms of metal content of new and under construction man-made deposits can be involved in production with increase in the wastelessness of subsoil development.

The aim of the research is to improve the quality of explosive crushing of ores for underground leaching of metals by experimentally substantiating the parameters of separation from the massif and crushing of metal ores.

Object: ore-bearing massif and technological processes of breaking and crushing of ores of a particular deposit during a full-scale experiment in a pilot block.

Methodology: critical analysis of the theory and practice of breaking and crushing ores for leaching in the store, organization of monitoring of the leached massif during the extraction of metals, modeling and interpretation of research results.

Results. The paper introduces a brief reference on the history of the issue and describes the technique of carrying out an industrial experiment at a deposit of exposed ores. The authors have systematized the indicators of explosive breaking of ores in their shoring and proposed a criterion of ore crushing by explosion. The mathematical processing of the results of ore blasting was carried out. It was shown that the leaching method, even with a recovery factor of $70 \%$, does not compete with traditional technologies due to the loss of a useful component and requires improvement. The regularities of useful component distribution in the classes of chipped ore, described by the logarithmic-normal Gauss law, were established. It is shown that the size of the piece, which corresponds to the arithmetic mean of the content of the useful component, objectively characterizes the quality of the ore chipped for underground leaching. The difference between the proposed method and the traditional calculation of the weighted average linear size, which does not take into account the uneven distribution of metal between fractions, is formulated. The authors proposed the generalized model of explosive preparation of ores for leaching. The study of the useful component content distribution in the chipped ore, depending on the material composition, the nature of mineralization, the total metal content in the ore-bearing rocks, the technology of ore preparation can have a significant impact on the leaching indicators.

\section{Key words:}

Industrial experiment, deposit, ore, metal, blasting, crushing, leaching, extraction, component distribution, lump size, content, model.

\section{REFERENCES}

1. Dmitrak Yu.V., Tsidaev B.S., Dzaparov V.Kh., Kharebov G.Kh. Mineral resources base of nonferrous metallurgy in Russia. Vector GeoNauk, 2019, vol. 2, no. 1, pp. 9-18. In Rus.

2. Gavrishev S.E., Kornilov S.N., Pytalev I.A., Gaponova I.V. Increasing the economic efficiency of mining enterprises due to the involvement of technogenic georesources in operation. Gornyi Zhurnal, 2017, no. 12, pp. 46-51. In Rus.

3. Espinoza R.D., Rojo J. Towards sustainable mining. P. I. Valuing investment opportunities in the mining sector. Resource Policy, 2017, vol. 52, pp. 7-18

4. Golik V.I., Lukyanov V.G., Khasheva Z.M. Substantiation of the possibility and expediency of using ore dressing tailings for the production of hardening mixtures. Bulletin of the Tomsk Polytechnic University, 2015, vol. 326, no. 5, pp. 6-14. In Rus.

5. Klyuev R.V., Bosikov I.I., Mayer A.V., Gavrina O.A. Comprehensive analysis of the use of effective technologies to improve the sustainable development of the natural and technical system. Sustainable development of mountainous territories, 2020, no. 2, pp. 283-290. In Rus.
6. Tayebi-Khorami M., Edraki M., Corder G., Golev A. Re-thinking mining waste through an integrative approach led by circular economy aspirations. Minerals, 2019, vol. 9, pp. 1-13. DOI: 10.3390 / $\min 9050286$

7. Lyashenko V.I., Golik V.I., Komashchenko V.I. Increasing the efficiency of drilling and blasting preparation of rock ores for underground block leaching of metals. Scientific and technical journal «Explosion Technology», 2018, no. 120/77, pp. 147-168.

8. Dubiński J. Sustainable development of mining mineral resources. International Journal of Sustainable Future for Human Security, 2013, vol. 12, no. 1, pp. 1-6.

9. Altushkin I.A., Korol Yu.A., Levin V.V., Bakin A.V. Extraction of copper from the mine waters of the Gumeshevskoe deposit. Tsvetnye Metally, 2019, no. 6, pp. 13-21. In Rus. DOI: $10.17580 /$ tsm.2019.06.02.

10. Komashchenko V.I., Dzaparov V.Kh., Dzeranov B.V., Stas G.V. Breaking of ores with modernized borehole charges. Vector GeoNauk, 2019, vol. 2, no. 3, pp. 40-46. In Rus.

11. Komashchenko V.I., Golik V.I., Belin V.A., Gaponenko A.L. Increasing the efficiency of blasting on the basis of new methods of 
initiation of borehole charges in open pits. Gorny information and analytical bulletin (scientific and technical journal), 2014, no. 9, pp. 293-304. In Rus.

12. Dmitrak Yu.V., Kamnev E.N. JSC «Leading design, survey and research institute of industrial technology» - a path long 65 years. Gornyi Zhurnal, 2016, no. 3, pp. 6-12. In Rus.

13. Cardu M., Seccatore J., Vaudagna A., Rezende A., Galvão F., Bettencourt J.S., Tomi de G. Evidences of the influence of the detonation sequence in rock fragmentation by blasting. P. I. REM: RevistaEscola de Minas, 2015, vol. 68, no. 3, pp. 337-342. DOI: 10.1590 / 0370-44672014680218.

14. Mngadi S.B., Durrheim R.J., Manzi M.S.D., Ogasawara H., Yabe Y. Integration of underground mapping, petrology, and highresolution microseismicity analysis to characterize weak geotechnical zones in deep South African gold mines. International Journal of Rock Mechanics and Mining Sciences, 2019, vol. 114, pp. 79-91.

15. Brigida V.S., Kozhiev H.H., Saryan A.A., Dzhioeva A.K. Spatiotemporal tasks of geoecology - an interdisciplinary approach. Gorny information and analytical bulletin (scientific and technical journal), 2020, no. 4, pp. 20-32. In Rus. DOI: 10.25018 / 023614932020-4-0-20-32.
16. Burmistrov K.V., Osintsev N.A. Principles of sustainable development of mining systems in transition periods. Bulletin of the Tomsk Polytechnic University. Geo Assets Engineering, 2020, vol. 331, no. 4, pp. 179-195. In Rus.

17. Ben-Awuah E., Richter O., Elkington T., Pourrahimian Y. Strategic mining options optimization: open pit mining, underground mining or both. International Journal of Mining Science and Technology, 2016, vol. 26, no. 6, pp. 1065-1071.

18. Domingues Maria S.Q., BaptistaAdelina L.F., Diogo Miguel Tato. Engineering complex systems applied to risk management in the mining industry. International Journal of Mining Science and Technology, 2017, vol. 27, pp. 611-616.

19. Rilnikova M.V., Vladimirov D.Ya., Pytalev I.A., Popova T.M. Robotic geotechnology as a way to improve the efficiency and greening the development of mineral resources. Physical and technical problems of the development of minerals, 2017, no. 1, pp. 92-101. In Rus.

20. Woodward K., Wesseloo J. Observed spatial and temporal behavior of seismic rock mass response to blasting. Journal of the Southern African Institute of Mining and Metallurgy, 2015, vol. 115, no. 11, pp. 1044-1056.

Received: 9 June 2021.

\section{Information about the authors}

Vladimir I. Golik, Dr. Sc., professor, chief researcher, Geophysical Institute of the Vladikavkaz Scientific Center of the Russian Academy of Sciences; professor, South Russian State Polytechnic University.

Yuri I. Razorenov, Dr. Sc., professor, Rector of the South Russian State Polytechnic University.

Vitaly I. Komashchenko, Dr. Sc., professor, South Russian State Polytechnic University.

Olga G. Burdzieva, Cand. Sc., head of the laboratory «Technogenic Geoecology», Geophysical Institute of the Vladikavkaz Scientific Center of the Russian Academy of Sciences. 